\title{
Probabilistic Model For Predicting Construction Worker Accident Based On Bayesian Belief Networks
}

\author{
Diah Sarasanty $^{1 *}$, Tri Joko Wahyu Adi ${ }^{2}$, I Putu Artama Wiguna ${ }^{2}$ \\ ${ }^{I}$ Master student at Institut Teknologi Sepuluh Nopember (ITS) Surabaya Indonesia \\ ${ }^{2}$ Lecturer at Institut Teknologi Sepuluh Nopember (ITS) Surabaya Indonesia \\ *Corresponding author: diahsarasanty@gmail.com
}

\begin{abstract}
The construction industry has a very important role to the growth of a country. The unique characteristics and dynamic nature of the construction industry lead to a dangerous condition and prone to accidents. The death rate due to accidents in the construction industry in 2015 increased by $4 \%$ compared to 2014 . The number of occupational accidents in Indonesia from year to year experienced a trend of an increase of 5\%. Unsafe behavior of workers was the main cause of $88 \%$ of accidents in the construction site, $10 \%$ due to unsafe conditions, and $2 \%$ due to the unavoidable things. In addition, the complexity of construction equipment and unsafe environment significantly determined the type of accident and severity of injuries. This study aims to propose the probability model to predict the construction worker accidents in construction projects. To improve the accuracy of the assessment of workplace accidents, Bayesian Belief Networks used as a study analysis to represent the relationship among unsafe factors such as unsafe behavior factors, unsafe environment and unsafe equipment that lead to accidents. The data was collected through project site survey, questionnaire, and interview to OSH Managers in ten construction projects. The validation is done by applying the model on four case of a high rise building. This finding shows both the probability and accurate prediction of work accidents with APE mean is 4,564 that is useful to assist the practitioners and all stakeholders especially those directly involved in construction industry and to get some recommendations steps and preventive actions in order to minimize the occurrence of fatal work accidents and improve occupational safety and health (OSH) as well as to contribute knowledge about the factors that influence the occurrence of accidents.
\end{abstract}

Keywords_ probability, construction projects, worker accident, unsafe factors, Bayesian Belief Networks.

\section{INTRODUCTION}

$\mathrm{T}_{\mathrm{he}}$ construction industry has a very important role to the growth of a country [1]. The unique characteristics and dynamic nature of the construction industry lead to a dangerous condition and prone to accidents [2-3]. The goal of construction project is not only influenced by the time's performance, cost and quality but also the safety aspect [4]. Annual total of 4,836 fatal workplace injuries in 2015 was the highest since 5,214 fatal injuries in 2008. Figure 1 presents the death rate due to accidents in the construction industry in 2015 increased by $4 \%$ compared to 2014 [5-6]. The occupational safety and health problem is generally neglected [7]. The number of occupational accidents in Indonesia from year to year experienced a trend of an increase of 5\% [7]. Unsafe behavior of workers was the main cause of $88 \%$ of accidents in the construction site, $10 \%$ due to unsafe conditions, and $2 \%$ due to the unavoidable things [9-13]. In addition, the complexity of construction equipment and unsafe environment significantly determined the type of accident and severity of injuries [19].

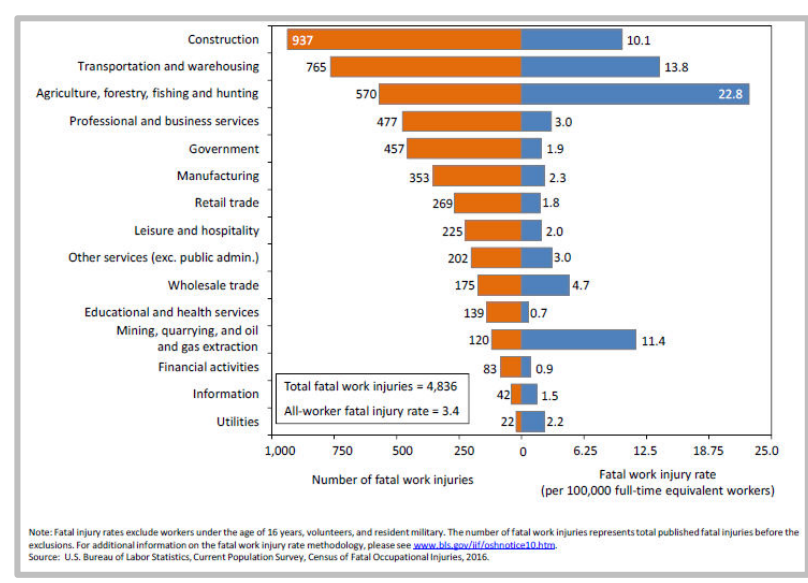

Figure 1. Number and rate of fatal work injuries by industry sector, 2015

To improve the accuracy of the working accident in construction project, the Bayesian Belief Network used in this study. Although most of previously mentioned studies have used structural equations modeling (SEM) [22], [25], fault tree analysis, event tree for modeling unsafe behavior, but these methods can not accommodate updating realtime events. BNN is another choice which can be used in this regard. BBN are a powerful and flexible tool for graphically modeling the causal interrelationships among some variables. The effectiveness of BNs in structuring causal graphical models has been making it a prominent tool in assessing and managing safety and health at workplaces. 
Bayesian Belief Networks (BBN) is probabilistic graph that combined probability and graph theory to explain the variables that have a high degree of linkages. BBN have several advantages which make it a promising tool for these purposes. BBN is very useful for prediction and diagnosis; this feature is very important in safety interventions because they are commonly expensive and their effects can only be observed in the long term. BBN capable to predict the effectiveness of an intervention strategy is a process known as "belief updating" by introducing new evidences, which is an important and unique advantage of $\mathrm{BBN}$ over other methods. The Bayes theorem is the basis of belief updating with new evidences [14].

Many studies have attempted to address issues related to construction workers accident. Some studies developed models to identify root causes of accidents based on the retrospective data [9-10], [26]. Recently, several studies have focused on identifying the critical factors and paths that influence construction worker accident.

Bayesian Belief Networks has been applied in many studies due to its ability to draw a conclusion by identifying the consequence which is expected from the uncertainty before building effective intervention [15]. A study conducted by Jitwasinkul used Bayesian analytical technique to improve secure working behaviour. A research done by Nguyen (2016) which focuses on the quantitative studies that uses Bayesian Belief Networks to develop prognostic approach to measure the risk of working accidents at heights. Mohammadfam uses Bayesian Belief Networks propose a model to develop and improve safe behavior in some of the electricity construction in Iran.

This study aims to to propose the probability model to predict the construction worker accidents in construction projects based on Bayesian Belief Networks that can be updated in real time according to conditions in the field. Whereas the purpose of more detailed research, namely:

1. To identify significant factors affecting the work accident of construction project.

2. To identify the relationship between significant factors affecting the work accident of construction project.

3. To inference probability and measure the accuracy of the construction worker accident prediction model of the construction project.

In addition, the output of this research is also to get the prediction of working accidents accurately in order to assist the practitioners and all stakeholders especially those directly involved in construction industry and to get some recommendations steps and preventive actions in order to minimize the occurrence of fatal work accidents and improve occupational safety and health (OSH) as well as to contribute knowledge about the factors that influence the occurrence of accidents.

\section{RESEARCH METHODOLOGY}

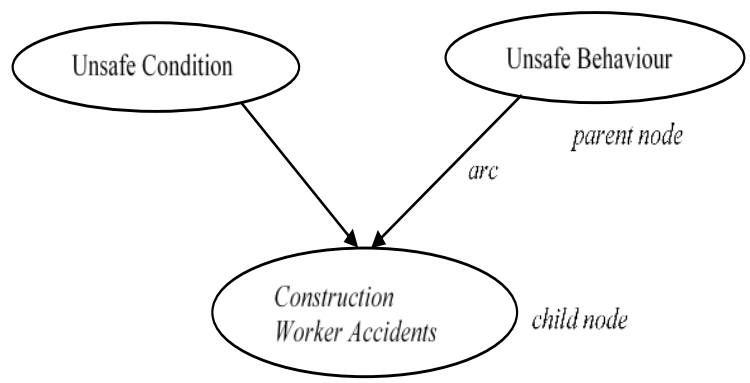

Figure 2. BBN simple structure of construction workers accident

Probabilistic modeling construction worker accident of the construction project consisted of several steps : Step 1. Created a model using Bayesian Belief Networks (BBN). Bayesian Belief Networks is a model to represent the uncertainty and probability theory to manage uncertainty. The most basic Bayes equation is [16-18]]:

$\mathrm{P}(\mathrm{Y} \mid \mathrm{X})=\frac{\mathrm{P}(\mathrm{X} / \mathrm{Y}) \mathrm{X} \mathrm{P}(\mathrm{Y})}{\mathrm{P}(\mathrm{X})}$

$\mathrm{P}(\mathrm{X})$ is the probability of $\mathrm{X}$, and $\mathrm{P}(\mathrm{Y})$ is the probability of $\mathrm{Y}$, and $\mathrm{P}(\mathrm{Y} \mid \mathrm{X})$ is the probability of $\mathrm{X}$ when $\mathrm{Y}$ is known events have occurred.

BBN describes the causal relationships among variables through the graphical model is a DAG (Directed Acyclic Graph). BBN consist of nodes that represent the variety of the domain, and arcs representing dependency relationships between nodes. Figure-2 shows the structure of a BBN simple, the node at the top of the arrow is called child nodes. Each node has a probability value in the form CPT (Conditional Probability Table) which is a quantitative component of Bayesian Belief Networks.

Table 1. Description of High Rise Building Construction Project

\begin{tabular}{lllll}
\hline Description & \multicolumn{1}{c}{ Project A } & \multicolumn{1}{c}{ Project B } & \multicolumn{1}{c}{ Project C } & \multicolumn{1}{c}{ Project D } \\
\hline Project type & Building project & Building Project & Building Project & Building Project \\
Owner & Private Company & BUMN Company & BUMN Company & Private Company \\
Project scope & 50 floors & 38 floors & 55 floors & 40 floors \\
\hline
\end{tabular}

Source : Secondary Data, 2017 


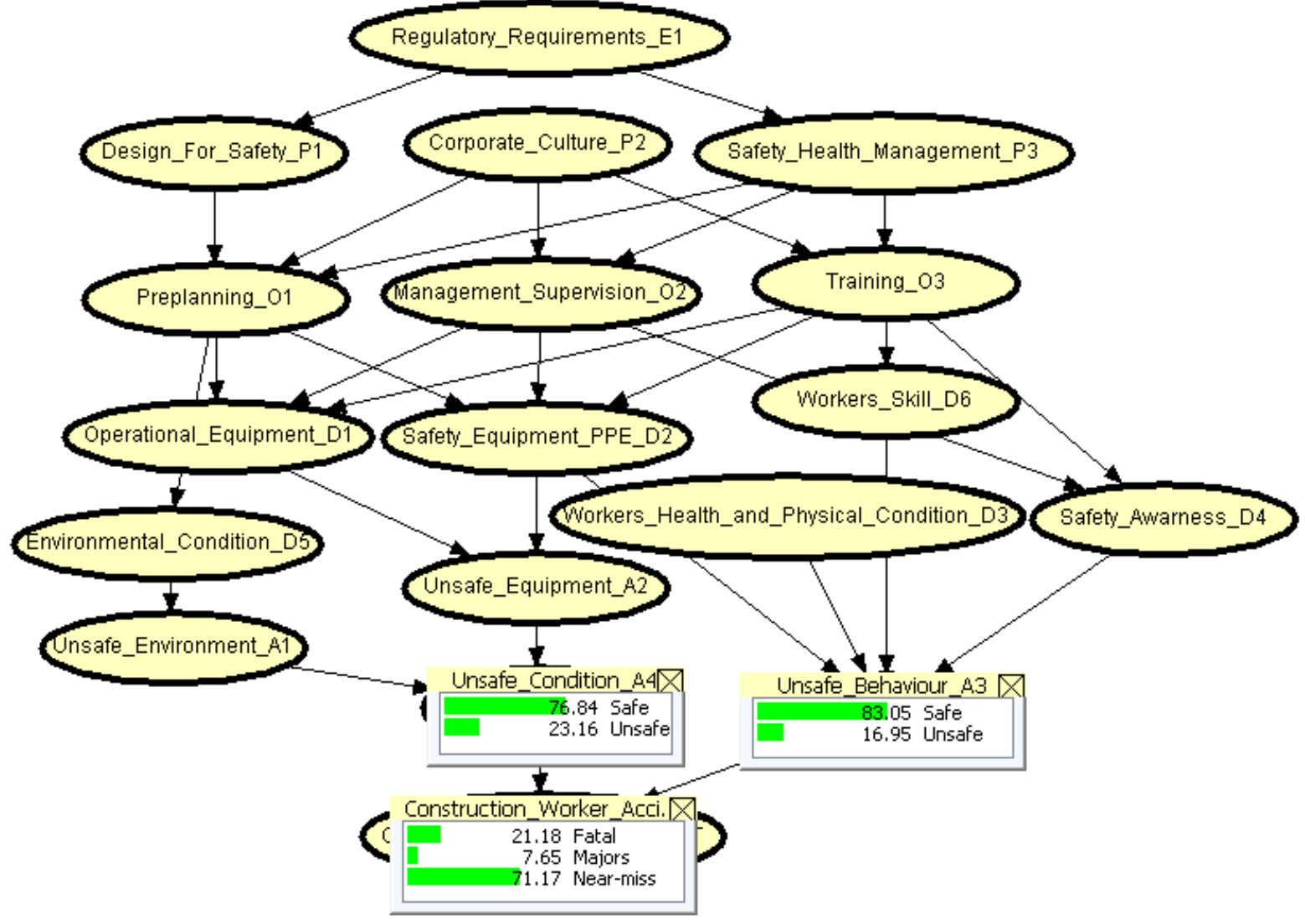

Figure 3. The conceptual BBN-based model for predicting construction workers accident (Building A)

accident of construction project. b) Factors through a method of filtering Focus Group Discussion (FGD). c) Obtaining significant factors to the work accidents in construction project. The most significant factors affecting the work accident of construction project based on the results on a literature review, location survey, questionnaire and an interview with construction expert (HSE Manager) namely : 1) regulatory requirements, [19-21], the framework of regulations, codes, standards, and guidance governing the industry and the profile and actions of the regulator. 2) design for safety, [19-22], the process of design of the structures to ensure constructability, operability and safety during the design and construction phases by external parties (A/E, suppliers, etc.) or by the contractor. 3) corporate culture, [19-21], the values, beliefs, norms, assumptions, experiences, traditions, business principles, ways of operating within an organization that influence the behavior of its members. 4) Safety and Health (S\&H) Management, [19], [23], [21], the management system which encompasses safety policies, procedures, the description of roles and responsibilities for safety, and performance measures to ensure, encourage, and evaluate safety performance 5) preplanning, [19], [21] the system that designs and structures work activities and assigns and allocates right resources to perform these activities 6) management and supervision, [19-21], the system that ensures human and other resources are adequately managed, supervised, and motivated 7) training, [19-25], the system that ensures the skills and capabilities of the workforce are matched to their job are available, conform to best practice, meet the usability needs of the operator/worker, and are inspected and maintained. 9) safety equipment and PPE, 21], [23], the extent to which safety equipment/personal protective equipment (PPE) are available, conform to best practice, meet the usability needs of the worker, and are inspected and maintained. 10) safety awareness, [24], [26], [27], [13], [21], the extent to which a worker perceives the hazards and risks associated with working at heights and acts safely. 11) environmental condition, [27], [24], [28], [26], [11], [29], [20], [21], The extent to which internal factors (such as noise, vibration, pressure) or external factors (weather, humidity, etc.) have an effect on the workplace activity. 12) worker's skills,[30], [21], the skills, experiences, and capabilities of the worker needed to perform a particular task safely and expectedly. 13) worker's health and physical condition, [24], [26], [27], [13], [21], worker' physical and spiritual mood when he/she is working. 14) unsafe environment, [33], is a physical and technical condition of an unsafe environment. 15) unsafe equipment, [22], is an unsafe condition of the equipment caused by improper installation, configuration and operation. 16) unsafe 


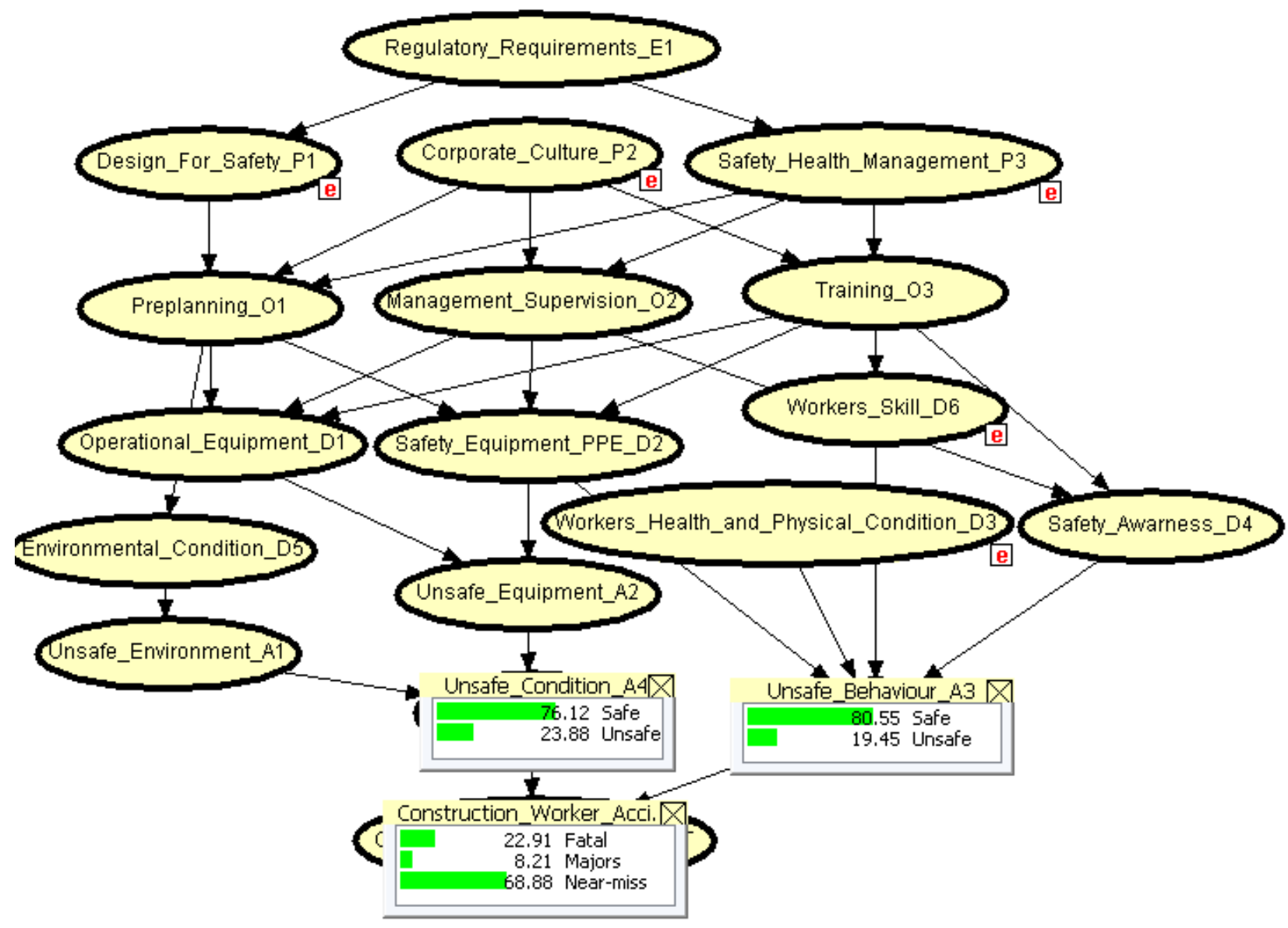

Figure 4. The BBN model for predict construction worker accident based on realtime condition (Building A)

behavior, [26], [29], [23], [12], [2], [31], [25], [14], defined as any behavior engaged in by an employee without considering safety rules, standards, procedures, instructions, and specified criteria in the system that can negatively influence the system safety or endanger the employee himself or his colleagues unsafe condition. 17) unsafe condition, [9], [22], [33], is a condition in which the physical layout of the workplace or work location, the status of tools, equipment, and/or material are in violation of contemporary safety standards. 18) construction worker accident, [Hinze, 1997], an unplanned, undesirable, unexpected, and uncontrolled event. d) Calculate the probability of construction worker accident through an inference process of models with elimination variable using BBN. This step using Bayes program. Step2. Model Validation, namely 1) the application of the model to high rise building of the construction project (case study). 2) the measurement of model accuracy is calculated using statistical formulas Absolute Percentage Error (APE).

$A P E=\left|\frac{y t-\tilde{y} t}{y t}\right| x 100$

where

$\hat{y} t=$ prediction value at year- $t$,

$y t=$ actual/real value at year- $t$

$\mathrm{t}=$ prediction period (year).

If the value of APE $<30$, the accurate prediction models tobe used [32]. 3) Discuss the results of the model validation.

Table 2. Results of the Average for Projects of High Rise Building A, B, C, and D

\begin{tabular}{l|c|c|c|c|c}
\hline \multicolumn{1}{c|}{ Project Name } & $\begin{array}{c}\text { Project of } \\
\text { Building A }\end{array}$ & $\begin{array}{c}\text { Project of } \\
\text { Building B }\end{array}$ & $\begin{array}{c}\text { Project of } \\
\text { Building C }\end{array}$ & $\begin{array}{c}\text { Project of } \\
\text { Building D }\end{array}$ & $\begin{array}{c}A P E \\
\text { Mean }\end{array}$ \\
\hline $\begin{array}{l}\text { The APE value of the construction workers } \\
\text { accident for fatal category }\end{array}$ & 8,17 & 0,31 & 8,10 & 5,06 & 5,41 \\
$\begin{array}{l}\text { The APE value of the construction workers } \\
\text { accident for majors category }\end{array}$ & 7,32 & 0,97 & 6,65 & 3,91 & 4,71 \\
$\begin{array}{l}\text { The APE value of the construction workers } \\
\text { accident for near-miss category }\end{array}$ & 3,22 & 0,42 & 7,30 & 3,34 & 3,57 \\
APE Mean & 6,23 & 0,56 & 7,35 & 4,10 & 4,564 \\
\hline
\end{tabular}




\section{RESULTS AND DISCUSSION}

\section{A. Structure of Bayesian Belief Network Model}

The most significant factor affecting the construction worker accident on the implementation of the construction project based on the literature review, location survey, interview (expert opinion) and questionnaires, namely 1) regulatory requirements, 2) design for safety, 3) corporate culture, 4) safety and health (S\&H) management, 5) preplanning, 6) management and supervision, 7) training, 8) operational equipment, 9) safety equipment and PPE, 10) safety awareness, 11) environmental condition, 12) worker's skills, 13) worker's health and physical condition, 14) unsafe environment, 15) unsafe equipment, 16) unsafe behavior, 17) unsafe condition, 18) construction worker accident. Conceptual model based on BBN to predict the probability of construction worker accident is presented in Figure 3. In figure 3, the construction worker accident is influenced directly by unsafe behaviour factors and unsafe condition.

The relationship among uncertainty factor is determined by the matrix dependency method through interview with construction expert (HSE Manager). Matrix method is used to describe the relationship between the parent nodes and the child nodes. Futhermore, the model parameters are determined that the probability quantitative factors affecting the construction worker accidents with questionnaire, interview, and expert opinion.

\section{B. Description of case studies}

BBN model validation is done by applying the models in the case of high rise building construction project A, B, C and D in the city of Surabaya, Indonesia. Description of the project is presented in Table-1.

\section{Prediction result of construction worker accidents}

The model is applied to the high rise building $\mathrm{A}, \mathrm{B}, \mathrm{C}$, and D project.

The validation is done by applying the $\mathrm{BBN}$ model validation on four case of a high rise building. In Figure 3 presents a model $\mathrm{BBN}$ project to predict the probability of the building A project of construction worker accident. The result of construction worker accident of the construction project is presented in Figure-3.

In the case of high rise building construction project A where real time conditions occurring indicate a major cause of work accident due incompetent trained workers, inadequate/unsecured design for safety.

Figure 4 shows The BBN model for predict construction worker accident based on real time condition. Probability values of BBN output for building A,B,C, and D are presented in Figure 5,6.

\section{Model Accuracy}

The model accuracy is calculated using statistical formulas APE, calculation results were presented in Figure 7, it shows that the value of $A P E<30$, proposed model is accurate. Value of the average $A P E$ for four building construction projects are presented in Table 2. The result of prediction of work accidents in construction projects is presented in Figure 7.

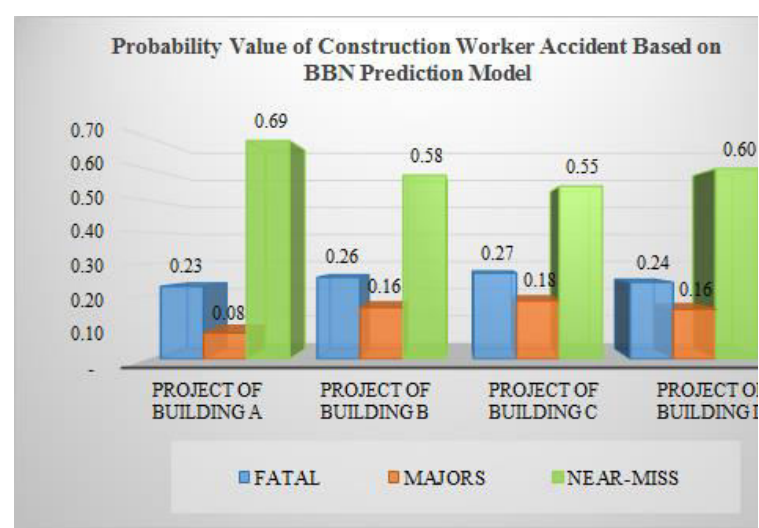

Figure 5. Probability Value of Construction Worker Accident Based On BBN Prediction Model

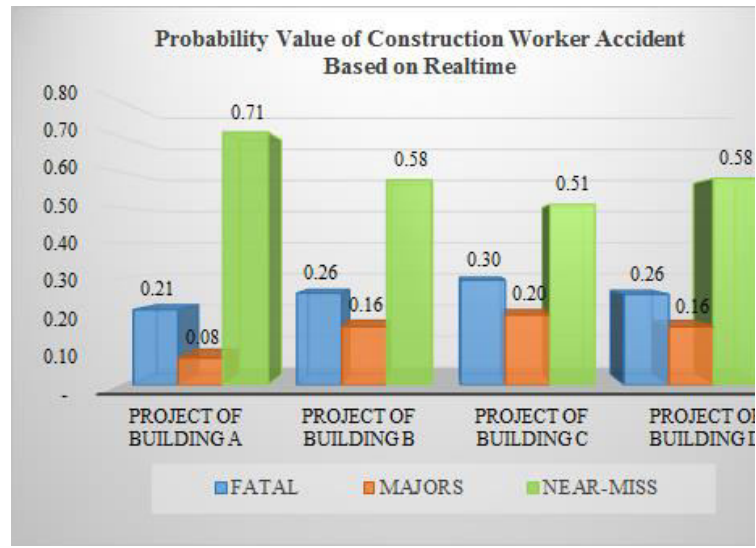

Figure 6. Probability value of Construction Worker

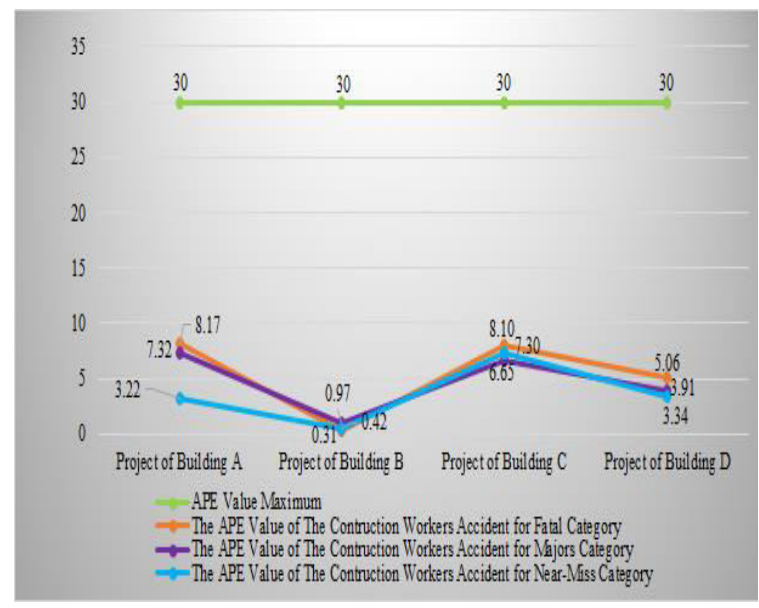

Figure 7. APE Calculation Results for Model Validation The Construction Worker Accident

Based on the result of model validation, the BBN models are proposed to predict the construction worker accidents gave good accuracy with APE mean is 4,564. This model can be used as the alternative method in predicting work accidents and as the recommendation steps as well as prevention to minimize the fatal work accidents.

According to [16], [18], et al (1998), BBN has some main benefits such as (1) BBN provides big flexibilities in capacity to receive input and give output, (2)BBN has the ability to allow the value of the variable 
to be entered known as the input or to evaluate the ability of the variable as output of the system (3) BBN can count easily the probability events before and after the evidences recognition and renew the diagnosis and prediction (4) BBN can be developed using experts' opinion and does not need historical data (5) BBN also allows variables to be added or removed without significantly affecting the rest of the network since the modifications to the network can be isolated and (6) BBN provides insight of the relationship among the variables from the process due to the graphic display.

\section{CONCLUSIONS}

Significant factors that directly affect the construction worker accident based on Bayesian Belief Networks are 1) unsafe behaviour, 2) unsafe condition. BBN models used as a study analysis to represent the relationship among unsafe factors that lead to accidents. The BBN model that has been built to predict construction worker accident illustrated that the relationship between the factors is not independent but interrelated as the prediction model proposed. Based on model validation result, the construction worker accident prediction gives good accuracy with APE mean is 4,564. Bayesian Belief Networks model is prediction model that can accommodate the updating of realtime events that is useful to minimize the occurrence of fatal work accidents and improve occupational safety and health $(\mathrm{OSH})$, therefore required factors' identification that influences work accidents in construction project. Finally, future research may need to consider different types and sizes of projects to investigate further the effectiveness of using the BBN approach to predicting and mitigating construction worker accident.

\section{REFERENCES}

[1] F. Murie, "Building Safety-An International Perspective," International Journal Occupational Environnment Health, vol.13, no.1. 2007.

[2] Andi, R.S. Alifen, and A. Chandra, "Structural Equation Model The Effects of Safety Culture on Worker Behavior in Construction Projects," Journal of Civil Engineering, vol. 12 , no. 3. 2005.

[3] R.D. Wirahadikusumah, "Challenges of Occupational Safety and Health Issues at Indonesia's Construction Project," FTSL, Institut Teknologi Bandung, Bandung. 2006.

[4] J. I. Alzahrani, and M. W. Emsley, "The impact of contractors' attributes on construction project success: A post construction evaluation," International Journal of Project Management, vol.31, pp. 313-322. 2013.

[5] International Labor Organization, "Occupational Safety and Health Management System : Training guide for managers and workers 5th edition Permenaker RI-1996," no.5. 2013.

[6] Bureau of Labor Statistic, "Employer-Reported Workplace Injuries And Illnesses - 2015," www.bls.gov/iif/oshsum.htm. 2016.

[7] Warta Ekonomi, "Occupational Safety and Health is underestimated," 2006.

[8] BpjsKetenagakerjaan, "The Number of Occupational Accidents in Indonesia increased," 2016.
[9] A.R. Abdelhamid, M.Z. Abd Majid, and B. Singh, "Causes Of Accidents At Construction Sites," Malaysian Journal of Civil Engineering, vol.20(2) : 242 - 259. 2000.

[10] A.Suraji, A. R. Duff, and S.J. Peckitt, "Development Of Causal Model Of Construction Accident Causation," Journal Construction Engineering Management, vol.127 : 337-344. 2001.

[11] R.A. Haslama, S.A. Hide, A.G.F. Gibb, D.E. Gyi, T. Pavitt, S. Atkinson, and A.R. Duff, "Contributing factors in construction accidents," Applied Ergonomics, vol.36, pp.401-415. 2005.

[12] S. Chi,Han, Sangwon, and K.D. Young, "Relationship between Unsafe Working Conditions and Workers' Behavior and Impact of Working Conditions on Injury Severity in U.S. Construction Industry," Journal of Construction Engineering and Management, vol. 139, no. 7. 2013

[13] Z. Jiang, , D. Fang, and M. Zhang, "Understanding the Causation of Construction Workers' Unsafe Behaviors Based on System Dynamics Modeling," Journal of Management in Engineering, , ISSN 0742-597. 2015.

[14] I. Mohammadfam, F. Ghasemi, O. Kalatpour, and A. Moghimbeigi, "Constructing a Bayesian network model for improving safety behavior of employees at workplaces," Applied Ergonomics, vol. 58, pp. 35-47. 2017.

[15] B. Jitwasinkul, B. H. W. Hadikusumo, and A. Q. Memon, "A Bayesian Belief Network model of organizational factors for improving safe work behaviors in Thai construction industry," Safety Science, vol. 82, pp. 264273. 2016.

[16] V. T. Luu, N. V. Tuan and S. O. Ogunlana, "Quantifying Schedule Risk in Construction Projects using Bayesian Belief Networks," International Journal of Project Management, vol.27 : 39-50. 2009.

[17] B. McCabe, S. M. AbouRizk, and R. Goebel, "Belief Networks for Construction Performance Diagnostic," Journal Computer Civil Engineering, ASCE, vol.12(2) : 93-100. 1998

[18] I. C. Cardenas, S. S. H. Al-Jibouri, and J. I. M. Halman, "A Bayesian Belief Networks Approach to Risk Control in Construction Projects," University of Twente, The Netherlands. 2012.

[19] Bomel, "Falls from height - Prevention and risk control effectiveness," Research Report 116. 2003.

[20] S. U. Han, S. H. Lee, and F. Pena-Mora, "System Dynamics Modeling of a Safety Culture," Construction Research Congress. 2010.

[21] L D. Nguyen, D Q. Tran, and M. P. Chandrawinata, "Predicting Safety Risk of Working at Heights Using Bayesian Networks the Journal of Construction Engineering and Management, ASCE, ISSN 0733-9364. 2016.

[22] Y. Zhang, W. Shao, M. Zhang, H. Lib, S. Yin, and Y. $\mathrm{Xu}$, "Analysis 320 coal mine accidents using structural equation modeling with unsafe conditions of the rules and regulations as exogenous variables," Accident Analysis and Prevention, vol. 92, pp. 189-201. 2016.

[23] D. Oswald, F. Sherratt, and S. Simon, "Exploring Factors Affecting Unsafe Behaviours In Construction," Procs 29th Annual ARCOM Conference, 2-4 September 2013, Reading, UK, Association of Researchers in Construction Management, pp. 335-344. 2013.

[24] D. C. Seo, "An explicative model of unsafe work behavior," Safety Science, vol. 43, pp. 187-211. 2005.

[25] J. Wang, P. X. W. Zou, and P. P. Li, "Critical factors and paths influencing construction workers' safety risk tolerances," Accident Analysis and Prevention, vol. 93, pp. 267-279. 2016. 
[26] A. R. A. Hamid, M. Z. A. Majid, and B. Singh, "Causes Of Accidents At Construction Sites," Malaysian Journal of Civil Engineering, vol. 20(2):242 - 259. 2008.

[27] N. D. Silva, and P. L. I. Wimalaratne, "OSH management framework for workers at construction sites in Sri Lanka," Engineering, Construction, and Architectural Management, vol. 19, no. 4. 2012.

[28] F. K.W. Wong, A. P.C. Chan, M. C. H. Yam, E. Y. S. Wong, K. T. C. Tse, K. K. C. Yip, dan E. Cheung, "Findings from a research study of construction safety in Hong Kong," Journal of Engineering, Design, and Technology, vol. 7, no. 2. 2009.
[29] Y. Khosravi, H. A. Mahabadi, E. Hajizadeh, N. H. Rangi, H. Bastani, and A. H. Behzadan, "Factors Influencing Unsafe Behaviors and Accidents on Construction Sites: A Review," International Journal of Occupational Safety and Ergonomics, vol. 20(1), no. 3-17. 2015.

[30] D. P. Fang, F. Xiea, X. Y. Huang, and H. Li, "Factor analysis-based studies on construction workplace safety management in China," International Journal of Project Management, vol. 22, no. 43-49. 2004.

[31] S. Makridakis, S. C. Wheelwright, and R. J. Hyndman, "Forecasting : Methods and Applications. 3nd Edition. John Wiley and Sons," New York, USA. 1998. 